\title{
Mobile learning application: flipped classroom
}

\author{
Aslina Baharum ${ }^{1}$, Lim Yi Wan ${ }^{2}$, Farashazillah Yahya ${ }^{3}$, Nadia Hanin Nazlah ${ }^{4}$, \\ Nor Azida Mohamed Nor ${ }^{5}$, Ismassabah Ismail ${ }^{6}$, Noorsidi Aizuddin Mat Noor ${ }^{7}$ \\ ${ }^{1,2,3}$ Faculty of Computing and Informatics, Universiti Malaysia Sabah, Malaysia \\ ${ }^{4}$ Faculty of Hotel \& Tourism Management, Universiti Teknologi MARA, Malaysia \\ ${ }^{5,6}$ Alam, SelangorFaculty of Computer and Mathematical Sciences, Universiti Teknologi MARA, Malaysia \\ ${ }^{7}$ UTM CRES, Faculty of Built Environment and Surveying, Universiti Teknologi Malaysia, Malaysia
}

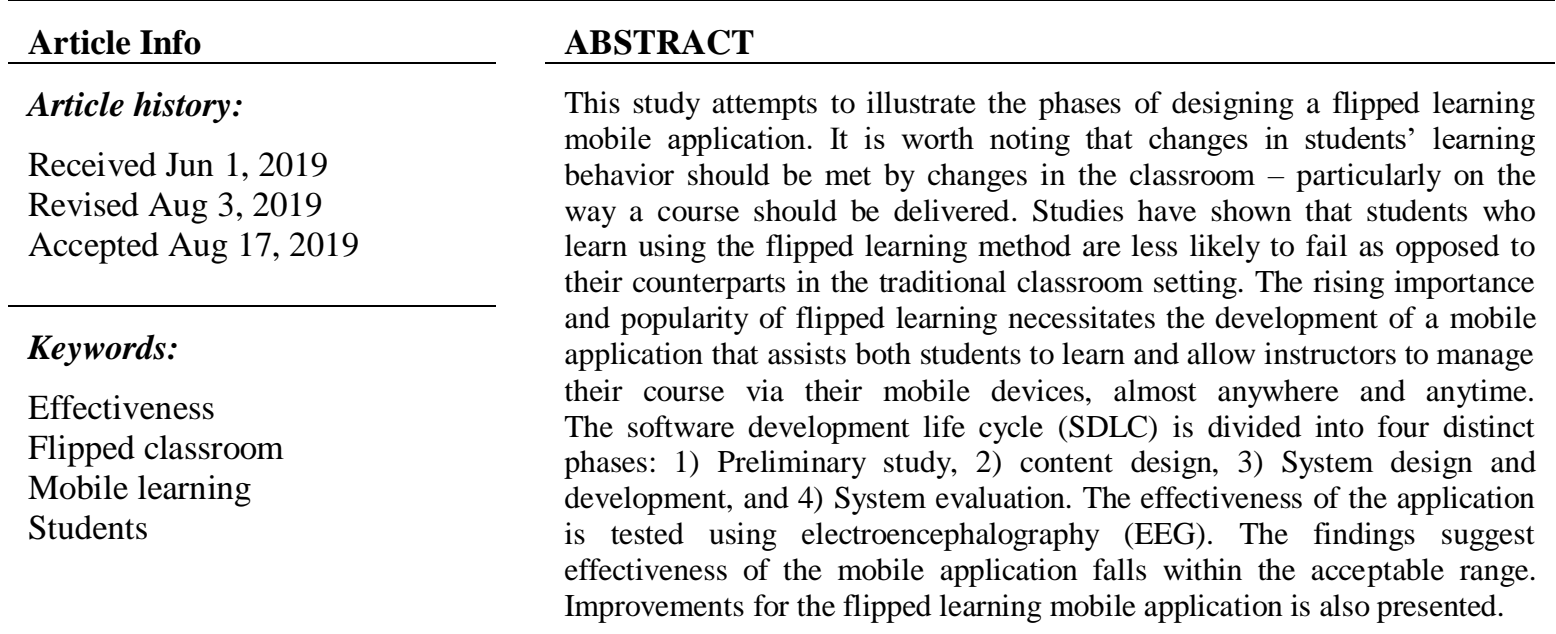

Copyright $@ 2020$ Institute of Advanced Engineering and Science. All rights reserved.

\section{Corresponding Author:}

Aslina Baharun,

Faculty of Computing and Informatics,

Universiti Malaysia Sabah,

88400 Kota Kinabalu, Sabah, Malaysia.

Email: aslina@ums.edu.my

\section{INTRODUCTION}

Technological advancements have contributed to the rising popularity of e-learning and mobile learning. With these learning methods, learners can access information anywhere and anytime, all at the touch of their fingertips. Universities are not exempted from joining the mobile-learning bandwagon to cater to learners' changing needs. Studies have revealed that students who were exposed to flipped learning have better grades and are $150 \%$ less likely to fail compared to their traditional classroom counterparts [1]. Students perceive one-way lectures in traditional classrooms as boring and inefficient.

A study found that Malaysian students expects to be spoon-fed by their instructors. These students relied heavily on textbooks and lecture notes, seldom involved in problem solving activities, rarely voice out their own ideas [2]. The flipped learning method attempts to get students to be actively involved in classroom activities. The adoption of the flipped learning methodology enables instructors to use class time for studentcentred learning activities that require higher-order thinking skills. Moreover, students are more excited to attend classes when they have control over theirs learning [3]. It is therefore timely to develop a mobile application that will support the flipped learning pedagogical approach that allows students to learn the materials prior class time, and instructors to manage their class materials.

The objective of this study is to illustrate the four phases undertaken by the researchers in developing a mobile application that assist both learners and instructors in the flipped learning classroom. 
The four phases of the software development life cycle are: 1) preliminary study, 2) content design, 3) system design and development, and 4) system evaluation using electroencephalography (EEG). Suggestions for improvements were also illustrated based on the findings of face to face interviews with the respondents.

\section{FLIPPED LEARNING}

In flipped learning, students' exposure to new materials takes place outside of the classroom, typically in an online environment. This allows for class time to be used for student-centred activities, allowing for collaboration, acquire interpersonal skills, think creatively, and communicate creatively [3, 4]. The continuously growing access to information on the Internet, traditional classroom settings of the teacher as a sage on the stage will soon become obsolete [5].

A comparison of the traditional classroom setting versus the flipped classroom is illustrated in Figure 1. In a traditional classroom, learning contents are delivered via lectures, and homework are assigned for students to complete outside of the classroom. The flipped learning classroom, students study the learning materials prior coming to class, reserving class time for inquiries, applications, and assessments. The main purpose of the flipped classroom is to allow greater focus on the application of knowledge and avoid students to become surface learners.

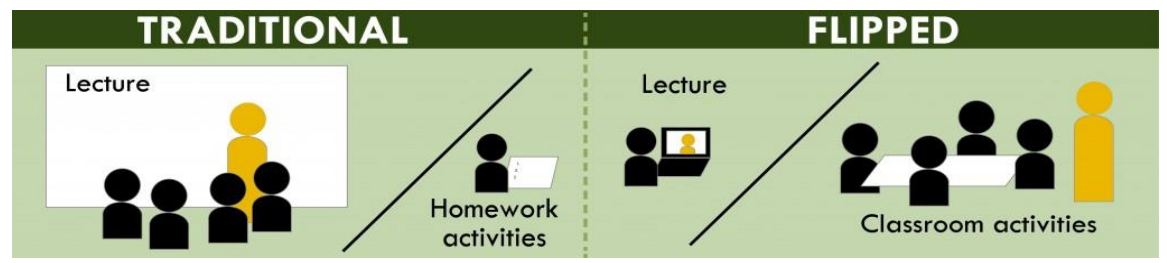

Figure 1. Traditional classroom and flipped classroom comparison

The flipped learning environment addresses individual needs. Students of varying abilities have control over theirs learning. Students can watch the learning materials as much or as little as they need, at their own convenience and speed. Students are able to stop, pause, rewind, and even replay materials for advanced concepts. Understanding the which topic that they require more help with allow for a more personalized tutoring with the instructor during class time [6-10].

In comparison to blended learning, traditional learning, and e-learning on self-efficacy, intrinsic motivation, perceived flexibility, and learners' performance, learners using the flipped learning method showed superior performance than the other three learning methods. The method also seemed to have positive effects on learners' self-efficacy and intrinsic motivation. Students who obtained better understanding before attending face-to-face sessions are engaged in higher level of cognitive processing $[4,10,11]$.

\section{RELATED WORKS}

A self-regulated flipped learning approach was developed by [12] to effectively read and understand learning materials prior class time so that learners would be capable of interacting with their peers and instructors for in-depth discussions. Figure 2 illustrates the learning flow of the self-regulated flipped learning approach. The instructor will introduce the syllabus, the self-regulated learning mode, and the flipped classroom method at the beginning of the course. Once the students understand the learning mode, a learning goal will be set based on students' prior learning experience. After completing the goal setting, students are then allowed to utilize the out-of-class learning system. The out-of-class learning system allows learners to read the e-books and attempt quizzes where ever and whenever. The learners' learning logs and performance are recorded in the database. Based on students' learning logs and performance, the instructor will conduct discussions that are appropriate with the learners' abilities. Face-to-face class time enables instructors to discuss any misunderstandings on the concepts, or error-prone questions.

On top of discussions, interactive learning activities are also conducted during class time. After completion of both in-class and out-of-class learning activities, learners are guided to perform selfevaluation in the self-regulated monitoring system. Upon completion, the database will provide learners with a diagnosis of theirs learning performance. Learners will then adjust their self-regulation accordingly. 


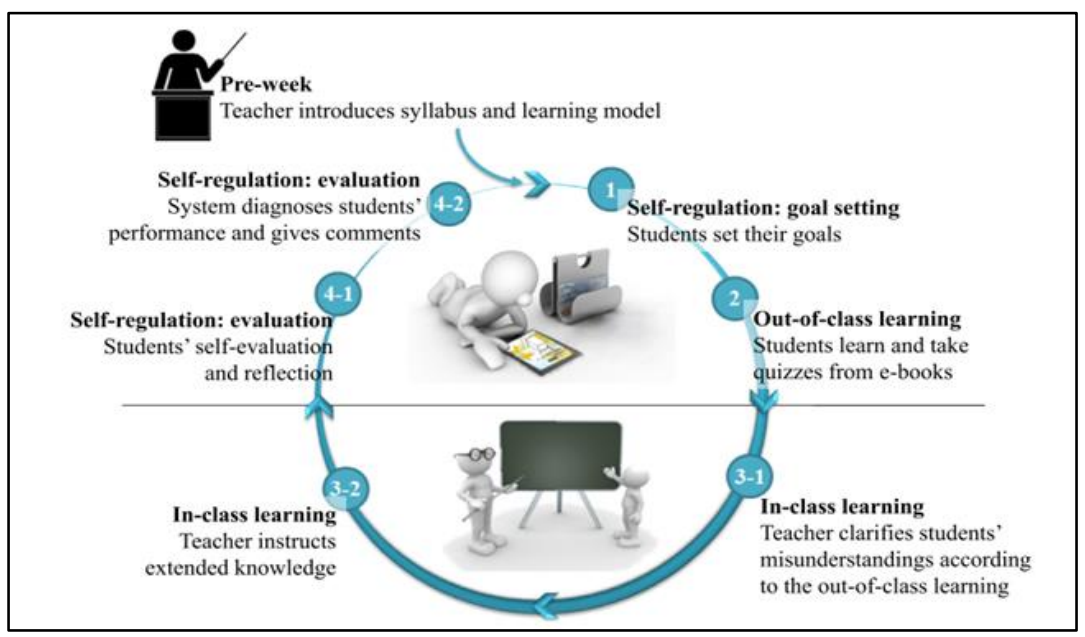

Figure 2. Learning flow of the self-regulated flipped classroom approach

\section{REVIEW OF EXISTING SYSTEMS}

To keep abreast with the current software demands, three existing systems (Khan Academy, edX, and OpenLearning) related to mobile-learning (M-Learning) were reviewed. Khan Academy is the most prominent pioneer among the new generation of digital learning organizations with almost 10 million unique visitors monthly [13]. EdX, developed through the collaboration of Ivy League universities are one of the main Massive Open Online Course (MOOC) platform with more than 15 million users worldwide [14]. In Malaysia, OpenLearning was elected as the official MOOC platform for all public higher learning institutions (HLIs). To prepare graduates for the $4^{\text {th }}$ industrial revolution, the Malaysian government aims to have at least $15 \%$ of public HLIs courses be taught online by 2015, leading to $30 \%$ in 2020 .

After reviewing the strengths and weaknesses of the functionality modules in each platforms, the researchers unanimously decided to include a discussion and quiz module, both of which were absent in all three platforms. The software, named as PokeLearn, have a register module, login module, and a manage profile module, similar to the three existing systems. On top of that, PokeLearn also includes a view progress module that enables instructors and students to track progress. The learn module and discuss module that is included in PokeLearn distinguishes the mobile application from Khan Academy, EdX and OpenLearning. The learn module allows instructors to create learning contents in multiple video and document formats such as .ppt, .pdf., .doc., .mp4, etc. Students need not download the learning contents to review them. The discuss module enables students to communicate with their instructor or peers via text or images in private chatrooms. This function allows students to get assistance when needed. This is different from an existing forum module on Open Learning where learners only have 'like' and 'comment' features that can be seen publicly.

\section{METHODOLOGY}

The software development begins with a preliminary study on the teaching methods currently being used in Malaysia. There are four phases in the SDLC, namely preliminary study, content design, system design and development, and evaluation. In the preliminary phase, the researchers construct the problem statement and review past literature in the areas of concern. There are three main activities conducted during this phase; a) analyze existing pedagogical approach commonly used in Malaysia, b) review types of educational applications, and c) identify the issues that exists in the adoption of existing applications. In the second phase, the researchers focus on content design. Similar to phase 1, there are also three main activities in the phase; a) review current technologies and tools used in mobile learning applications, b) study existing MOOC mobile learning applications, and c) design the learning contents for a Technopreneurship course on the OpenLearning platform. The output of this phase is the complete learning materials for Technopreneurship. In phase three, the researchers focuses on system design and development that comprises of five major activities; a) questionnaire development, b) application flow design, c) database design, d) user interface design, and e) system development. The evaluation of the application was conducted in the final phase using EEG. The three main activities in the final phase; a) verification and validation, b) post-project survey, and c) data collection on the new system. 


\section{IMPLEMENTATION OF FLIPPED CLASSROOM}

A flipped classroom approach is implemented post development of the M-Learning application. Figure 3 demonstrate the interface for all of the modules in the application. The pilot course for this project is a Technopreneurship course that being offered to second year bachelor's degree students. This is the reason why the researchers had to prepare learning materials for this course on OpenLearning in phase 2. Completed learning materials are then uploaded to PokeLearn. Students enrolled in the course are instructed to study the course materials prior class time. At the start of the class, students are required to complete an assignment or quiz to gauge their readiness and understanding of the topic. The instructor then guides the students through series of inquiries, activities and discussions.
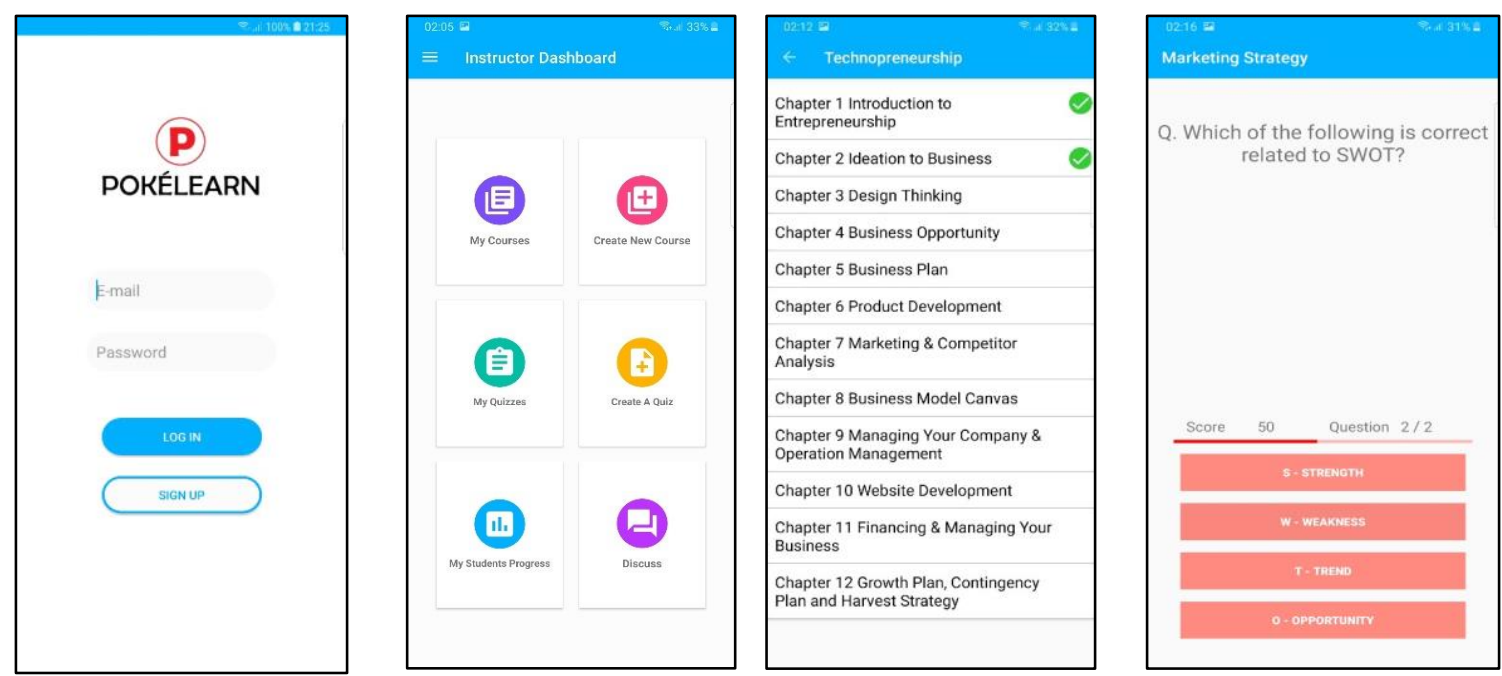

Figure 3. Mobile application (pokelearn)

\section{EVALUATION}

The researcher used the Effective Learner application to evaluate PokeLearn's effectiveness. Neurosky Mindwave headset were used to monitor learning effectiveness by measuring learners' focus levels. The headset detects tiny electrical impulses, or brainwaves and analyze it using the Effective Learner application. An Effectiveness Tracker shows current focus level and learning effectiveness using six colorcoded levels [15], and provides a session report that includes the time plot of the effectiveness during the study duration with a pie chart showing percentages in different colors. Figure 4 illustrates the learning effectiveness scale. Learning effectiveness is represented by six colors from red to blue, with red being least effective, and blue being most effective. Upon completion of the evaluation, individuals were interviewed on their experience of using PokeLearn.
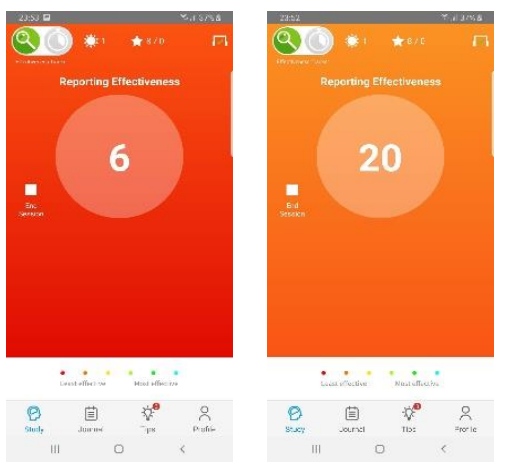

Least effective
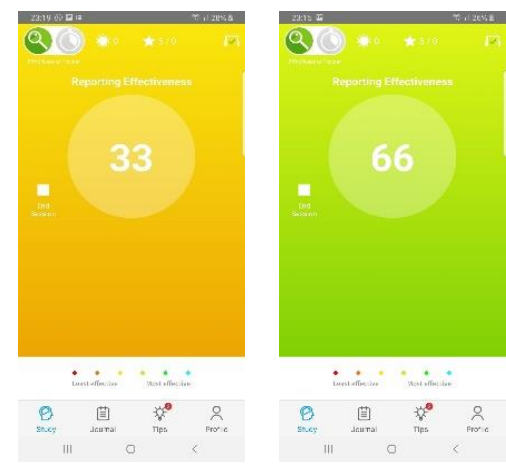

Most effective
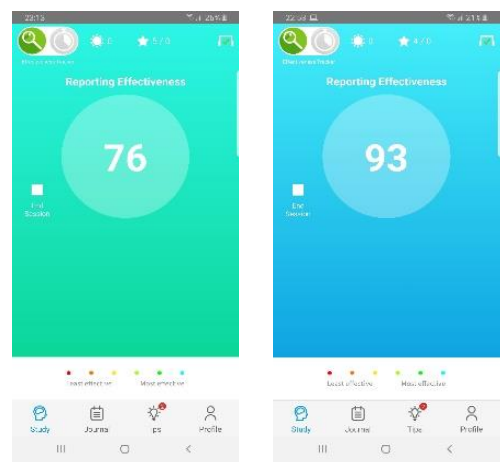

Figure 4. Learning effectiveness scale 
Prior testing, respondents were briefed on the tasks they need to complete on PokeLearn. The tasks given are illustrated in Table 1. Respondents were given the brainwave headset for them to put on before being given mobile devices that are pre-installed with PokeLearn. Respondents can begin completing the tasks given once the Effective Learner application detects brainwave readings.

Table 1. Respondents' Tasks

\begin{tabular}{cl}
\hline No. & \\
\hline 1. & Register an account \\
2. & Search for Technopreneurhsip course \\
3. & Enroll into the course \\
4. & Learn Chapter 7 (Marketing and Competitor Analysis) of the Technopreneurship \\
5. & Take a quiz on Chapter 7. \\
6. & Add a friend in the discussion function. \\
7. & View the progress of the course taken. \\
\hline
\end{tabular}

Upon completion, respondents are required to fill up their personal data comprises of their name, age, and gender. Once they have completed all tasks, they are interviewed on theirs learning experience using PokeLearn.

\section{DATA COLLECTION}

The effectiveness of the PokeLearn mobile application was evaluated by 10 respondents. Respondents' demographic profile, screenshots of user testing session reports, and interview responses is illustrated in Figure 5.

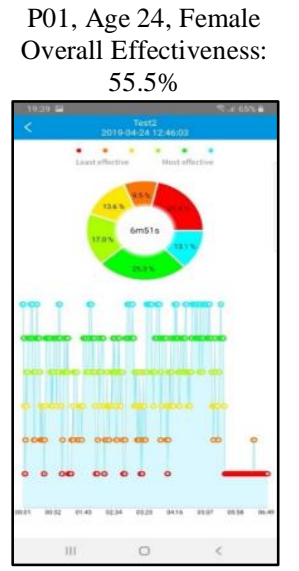

P06, Age 24 , Male Overall Effectiveness: $73.3 \%$

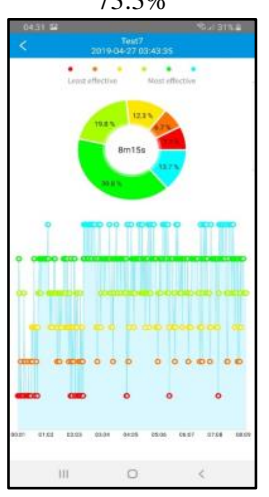

P02, Age 22, Female Overall Effectiveness: $50.1 \%$

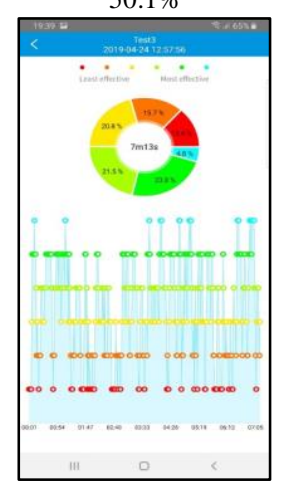

P07, Age 24, Male Overall Effectiveness: $67.3 \%$

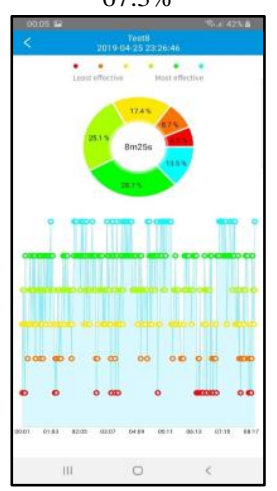

P03, Age 23, Male Overall Effectiveness:

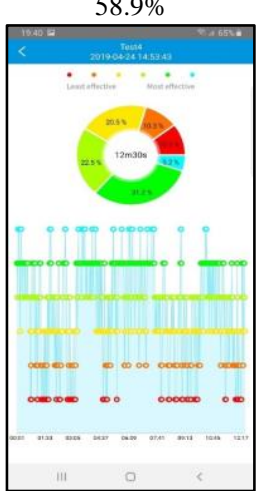

P08, Age 24, Male Overall Effectiveness: $70.4 \%$

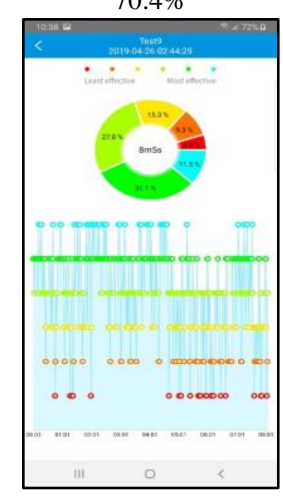

P04, Age 24, Male Overall Effectiveness: $69.1 \%$

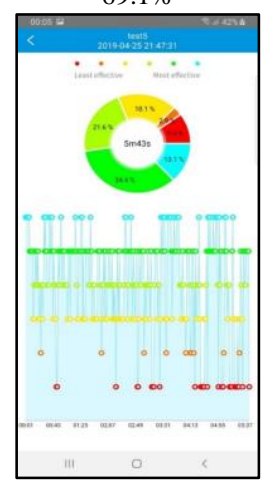

P09, Age 24, Female Overall Effectiveness: $66.8 \%$

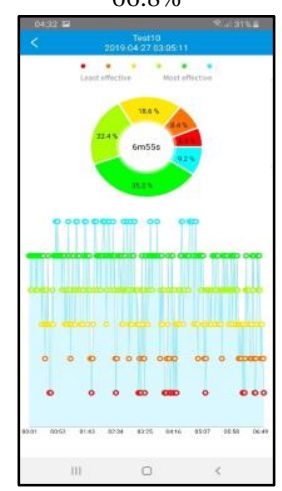

P05, Age 24, Male Overall Effectiveness:

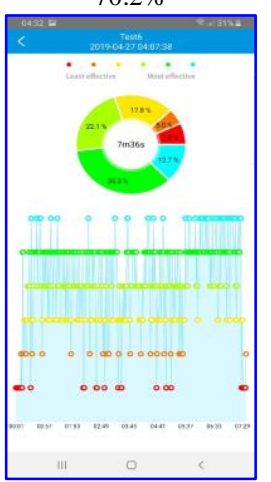

P10, Age 24, Female Overall Effectiveness: $75.9 \%$

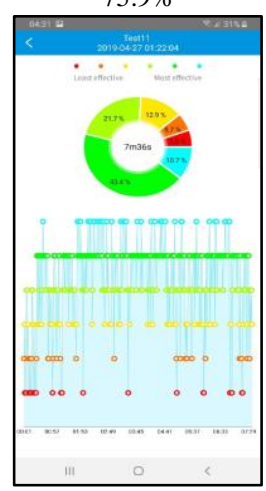

Figure 5. User testing session report 


\section{FINDING AND DISCUSSION}

The respondents' demographic profile shows that $60 \%$ of the respondents are male. $80 \%$ of the total respondents are 24 years old. Respondents' total learning time ranges between 5 minutes 43 seconds and 12 minutes 30 seconds, which is within the recommended duration of M-learning of between 3 to 15 minutes [16-18]. The minimal learning times is expected as M-learning is anticipated to occur while learners are in between activities (waiting for a bus, in a coffee shop, waiting for laundry, etc.). The results suggest that the PokeLearn's effectiveness is between $50.1 \%$ to $75.9 \%$, with an average effectiveness of $65.75 \%$ that is well within the effective range. All 10 respondents gave positive feedback about flipped learning, as well as on PokeLearn's interface. Findings from an interview with the respondents revealed that the respondents believe that flipped learning will enhance students' performance. Respondents suggested that user experience could be further improved with offline capabilities, gaming elements and assessment reviews.

\section{CONCLUSION}

The ever changing needs of learners call for a change in teaching methodologies. Learners today are easily distracted with the abundance of information that can be assessed online, therefore it is the responsibility of the instructors to teach using methodologies that would encourage students' engagement [19-21]. Findings of this study indicate that the flipped learning method assisted by M-Learning application does increase learning effectiveness [22-25].

\section{ACKNOWLEDGEMENT}

Researchers are thankful to Universiti Malaysia Sabah (UMS) for the support of the resources and necessary facilities for the preparation of the research. This study is currently funded by a UMSGreat Grant from Universiti Malaysia Sabah (GUG0299-2/2018).

\section{REFERENCES}

[1] Freeman, S., Eddy, S. L., McDonough, M., Smith, M. K., Okoroafor, N., Jordt, H., \& Wenderoth, M. P, "Active learning increases student performance in science, engineering, and mathematics, " Proceedings of the National Academy of Sciences, 111(23), 8410-8415. Retrieved from https://doi.org/10.1073/pnas.1319030111 (2014).

[2] Fung Lan Yong. (2010). "A study on the learning approaches of Malaysian students in relation to English Language acquisition",Fromhttps://www.researchgate.net/publication/260762634_A_study_on_the_learning_approaches_of_ Malaysian_students_in_relation_to_English_Language_acquisition, Retrieved October 18, 2018,

[3] Hazlina Aziz. (2015). "Flip" your classroom | New Straits Times | Malaysia General Business Sports and Lifestyle News, from https://www1.nst.com.my/news/2017/03/119357/flip-your-classroom, Retrieved October 18, 2018.

[4] Thai, N. T. T., De Wever, B., \& Valcke, M, "The impact of a flipped classroom design on learning performance in higher education", Looking for the best "blend" of lectures and guiding questions with feedback. Computers and Education, 107, 113-126. Retrieved from https://doi.org/10.1016/j.compedu.2017.01.003, (2017).

[5] Jenkins, M., Bokosmaty, R., Browne, C., Hanson, J., \& Kupatadze, K, "Enhancing the Design and Analysis of Flipped Learning Strategies“. Retrieved from https://doi.org/10.20343/teachlearninqu.5.1.6, (2017).

[6] Embi, M. A. Blended \& Flipped Learning, "Case Studies in Malaysian HEIs of Education Malaysia". Retrieved from https://www.moe.gov.my/images/Terbitan/Buku-informasi/Blended-Flipped-Learning-Case-Studies-inMalaysian-2014/Blended \& Flipped Learning-Case Studies in Malaysian HEIs_OnlineVersion26112014. pdf, (2014)

[7] Bishop, J. L., \& Verleger, M. A, "The Flipped Classroom A Survey of the Research“. Retrieved from https://doi.org/10.1109/FIE.2013.6684807, (2013).

[8] Johnson, G. B, "Student perceptions of the Flipped Classroom, Retrieved from https://doi.org/10.14288/1.0073641, (2013).

[9] Kong, S. C, "Developing information literacy and critical thinking skills through domain knowledge learning in digital classrooms", An experience of practicing flipped classroom strategy. Computers \& Education, 78, 160-173. Retrieved from https://doi.org/10.1016/J.COMPEDU.2014.05.009, (2014)

[10] Roach, T, Student perceptions toward flipped learning, "New methods to increase interaction and active learning in economics". International Review of Economics Education, 17, 74-84. Retrieved from https://doi.org/10.1016/J.IREE.2014.08.003, (2014).

[11] Gilboy, M. B., Heinerichs, S., \& Pazzaglia, G. (2015). "Enhancing student engagement using the flipped classroom", Journal of nutrition education and behavior,47(1), 109-114.

[12] Lai, C. L., \& Hwang, G. J, “A self-regulated flipped classroom approach to improving students' learning performance in a mathematics course", Computers \& Education, 100, 126-140, (2016).

[13] Robert Murphy, Lawrence Gallagher, Andrew Krumm, Jessica Mislevy, Amy Hafter, M. P, "Research on the Use of Khan Academy in Schools". Retrieved from https://www.sri.com/sites/default/files/publications/2014-0307_implementation_briefing.pdf, (2014) 
[14] Sanchez-Gordon S., Luján-Mora, S, "How Could MOOCs Become Accessible? The Case of edX and the Future of Inclusive Online Learning“. https://pdfs.semanticscholar.org/423a/0abb19dbee39af536235293d775c7982b231.pdf, (2016).

[15] Truong, H., Francisco, A., Khosrowpour, A., Taylor, J.E., Mohammadi, N. (2017). "Method for visualizing energy use in building information models. In Proceeding of 9th International Conference on Applied Energy", ICAE2017, 21-24 August 2017, Cardiff, UK, Energy Procedia 142, 2541-2546.

[16] Ghosh, S. (2016). "mLearning, The Chance To Enhance Education In Developing Nations". Educational Technology. Retrieved from: https://elearningindustry.com/mlearning-chance-enhance-education-in-developingnations

[17] Adamu, M. S, "Developing a Mobile Learning App: A User - Centric Approach. Proceedings of the First African Conference on Human Computer Interaction - AfriCHI'16". Retrieved from https://doi.org/10.1145/2998581.2998602, (2016)

[18] Hartnett, M, "Motivation in Online Education", (2010), 5-33. Retrieved from Retrieved from https://doi.org/10.1007/978-981-10-0700-2, (2016).

[19] Gasah, M., and Aslina, B, "A Conceptual Framework for Emotional Connection towards E-learning Mobile Application Design for Children“. Journal of Software \& Systems Development, Vol. 2018, Article ID 372543, 17 pages. DOI: 10.5171/2018.372543, (2018).

[20] Rahim, R.H.A., Baharum, A., Hijazi, M.H.A, “Mobile Application Calculator for Inverse Method and Cramer's Rule at Polytechnic Kota Kinabalu“, Journal of Fundamental and Applied Sciences, 10(7(S), pp. 132-142. doi: http://dx.doi.org/10.4314/jfas.v10i7s.11, (2018)

[21] Turumugon, P., and Aslina, B, "Identifying a User Interface Web Design Standard for Higher Learning Institutions Using Kansei Engineering", Indonesian Journal of Electrical Engineering and Computer Science, Vol. 11, No. 1, pp. 90-97. ISSN: 2502-4752, DOI: 10.11591/ijeecs.v11.i1.pp90-97, (2018).

[22] Kim, M. K., Kim, S. M., Khera, O., \& Getman, J, "The experience of three flipped classrooms in an urban university", An exploration of design principles. Internet and Higher Education, 22, 37-50. Retrieved from https://doi.org/10.1016/j.iheduc.2014.04.003, (2014)

[23] Wong, H. C, "A study of mobile learning for higher education students in Guangzhou“. SpringerPlus, 3(Suppl 1), P3. Retrieved from https://doi.org/10.1186/2193-1801-3-S1-P3, (2014).

[24] Yousuf, M. I, "Effectiveness of Mobile Learning in Distance Education“, Turkish Online Journal of Distance Education, Retrieved from https://files.eric.ed.gov/fulltext/ED499346.pdf, (2007)

[25] Gasah, M., Zain, N.M.M., Aslina, B, “An approach in creating positive emotion for children's e-learning based on user interface design“. Indonesian Journal of Electrical Engineering and Computer Science, Vol. 13, No. 3, pp. 1267-1273. ISSN: 2502-4752, DOI: 10.11591/ijeecs.v13.i3.pp1267-1273, (2019) 